\title{
1,3,5-三嗪烷合成含氮杂环的反应研究进展
}

\author{
张建涛* 周 鹏 肖朵朵刘卫兵* \\ (广东石油化工学院化学学院 广东茂名 525000)
}

\begin{abstract}
摘要 $1,3,5$-三嗪烷是一类重要的合成子, 可看成是甲醛亚胺的等价物，参与各类含氮杂环骨架的构建. 近年来，1,3,5三嗪烷在含氮杂环化合物的构建中引起了越来越多的关注. 基于此，系统综述了 1,3,5-三嗪烷作为双原子、三原子以及 四原子合成子参与 $[2+n],[3+n],[4+n]$ 环加成反应构建含氮杂环化合物的反应研究进展, 总结了其在环加成、杂环化 学以及药物化学中的应用, 并展望了基于 1,3,5-三嗪烷参与构建含氮杂环骨架及其应用的未来发展趋势.

关键词 1,3,5-三嗪烷; 含氮杂环; 合成子; 环加成反应; 药物化学
\end{abstract}

\section{Research Progress of 1,3,5-Triazinanes in the Synthesis of Nitrogen-Containing Heterocycles}

\author{
Zhang, Jiantao* Zhou, Peng Xiao, Duoduo Liu, Weibing* \\ (College of Chemistry, Guangdong University of Petrochemical Technology, Maoming, Guangdong 525000)
}

\begin{abstract}
Triazinanes are an important class of synthons, which could be regarded as the equivalent of formaldehyde imines in constructing various nitrogen-containing heterocyclic skeletons. In recent years, 1,3,5-triazinanes have attracted much attention in the construction of nitrogen-containing heterocyclic compounds. Based on this, the participation of 1,3,5-triazinanes as diatomic, triatomic and four-atom synthons in $[2+n],[3+n],[4+n]$ cycloaddition reactions to construct nitrogen-containing heterocyclic compounds is systematically summarized. Its applications in cycloaddition, heterocyclic chemistry and pharmaceutical chemistry are also summarized. Moreover, the development of 1,3,5-triazinanes in the construction of nitrogen-containing heterocyclic skeletons and their future applications are also prospected.

Keywords 1,3,5-triazinane; nitrogen-containing heterocycle; synthon; cycloaddition reaction; pharmaceutical chemistry
\end{abstract}

杂环化学已成为有机化学必不可少的子学科, 并且 杂环已发展成为市售药物和药物发现过程的药用靶标 中最常见的结构基序. 它们是许多药物/药物制剂的重 要组成部分, 例如天然产物、激素、抗生素、抗癌药、 抗病毒药、维生素等. 氮杂环是药物中最重要的结构成 分之一, 对药物化学做出了重大贡献. 在过去的几年中, 芳杂环有机化合物的开发和药理学引起了科研工作者 极大的兴趣, 例如吲哚、咔唑、苯并咪唑、苯并噻唑、 噁二唑、咪唑、异噁唑、吡唑、三唑、喹啉和喹唑啉 等 ${ }^{[1]}$. 含氮杂环化合物的构建不仅可以推动有机合成尤 其是药物合成的发展, 还可以极大地丰富药物分子的种 类, 为新药研发提供更多的可能, 从而推动药物化学的
发展. 因此, 开发高效和简便的合成含氮杂环的方法一 直以来是化学家们研究的热门课题.

另一方面, 1,3,5-三嗪烷由于其稳定性、结构多样性 以及易于制备和处理而成为有吸引力的合成砌块. 该类 化合物可由多聚甲醛和胺类化合物发生缩合反应制 备 ${ }^{[2]}$. 1,3,5-三嗪烷可分解成带有亲核氮和亲电子碳原子 的甲醛亚胺稳定前体(Scheme 1), 近年来，1,3,5-三嗪烷 在含氮杂环化合物的构建中引起了越来越多的关注 ${ }^{[3]}$. 1,3,5-三嗪烷可看成是甲酫亚胺的等价物，用作有效的 氨基甲基化试剂和曼尼希型试剂[4-10]; 1,3,5-三嗪烷还可 以作为双原子、三原子以及四原子合成子，参与 $[2+n]$ 、 $[3+n]$ 或者 $[4+n]$ 环加成反应，构建五元、六元及七元等

\footnotetext{
* Corresponding authors. E-mail: zhangjt@gdupt.edu.cn; 1wb409@gdupt.edu.cn Received July 9, 2021; revised August 11, 2021; published online August 24, 2021.

Project supported by the Projects of Talents Recruitment of Guangdong University of Petrochemical Technology (Nos. 2019rc048, 2017rc07), the Program for Innovative Research Team of Guangdong University of Petrochemical Technology (No. 519124), and the Ordinary University Young Innovative Talents Project of Guangdong Province, China (No. 2018KQNCX167).

广东石油化工学院人才引进计划(Nos. 2019rc048，2017rc07)、广东石油化工学院创新研究团队(No. 519124)和广东省普通高校青年创新基金(No. 2018KQNCX167)资助项目.
} 


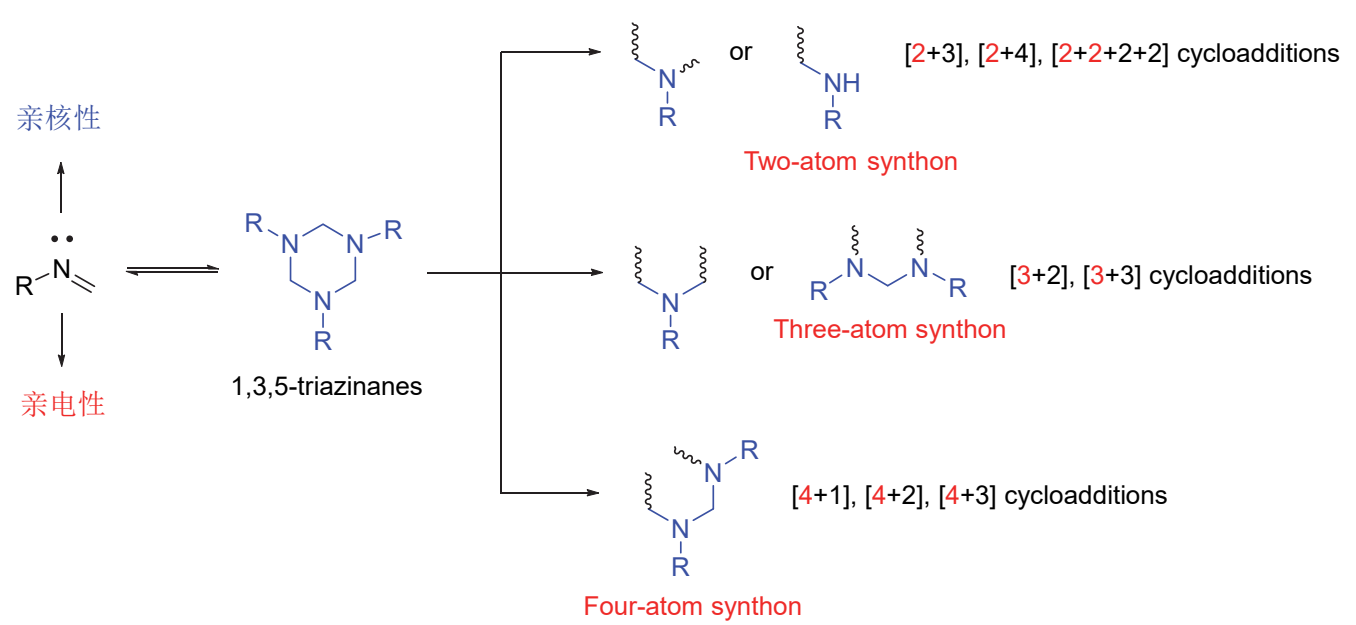

图式 1 1,3,5-三嗪烷的多种反应模式

Scheme 1 Diverse reaction patterns of 1,3,5-triazinanes

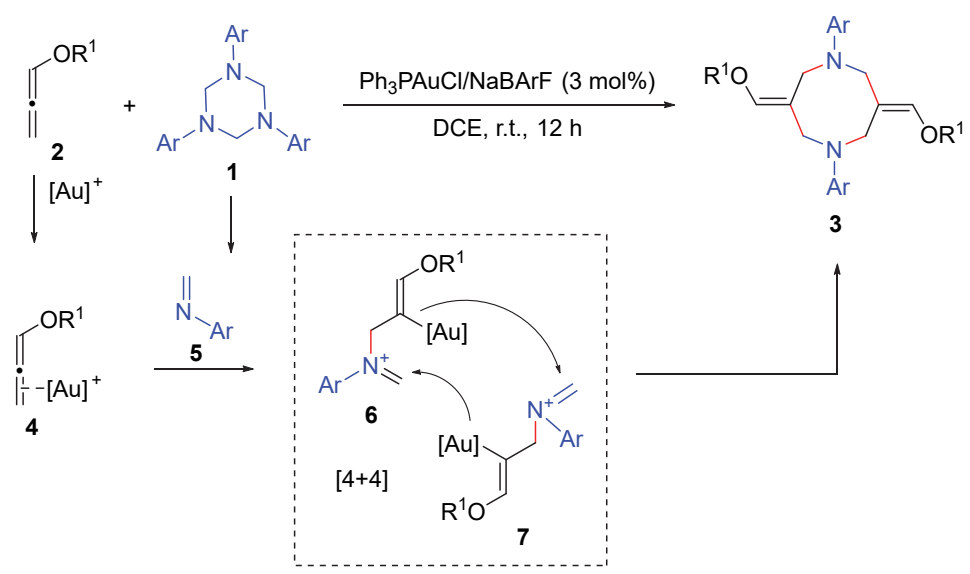

图式 2 金催化 1,3,5-三嗪烷[2+2+2+2]环加成

Scheme 2 Au-catalyzed $[2+2+2+2]$ cycloaddition of 1,3,5-triazinanes

含氮杂环化合物(Scheme 1). 国内外很多学者都对 1,3,5三嗪烷进行了相关的研究, 并取得了丰硕的成果, 本文 结合近几年国内外研究报道, 对 1,3,5-三嗪烷参与合成 含氮杂环骨架的环化反应研究进展进行较系统的综述, 希望对该领域的发展起到一定的促进作用.

\section{1 作为双原子合成子}

2017 年, 孙江涛课题组 ${ }^{[11]}$ 报道了一种金催化联烯 醚和 1,3,5-三嗪烷[2+2+2+2]环化的反应(Scheme 2 ). 该反应以三苯基膦氯化亚金(I)为催化剂, 1,2-二氯乙烷 为溶剂, 室温下以较高的收率合成了一系列八元含氮杂 环骨架 3. 该反应适用于各种烷基、芳基以及硅基醚取 代的联烯.

Donor-Acceptor (D-A)环丙烷在 Lewis 酸作用下，常 常作为 1,3-偶极子, 通过 $[3+n]$ 环化反应模式, 参与环 状化合物的构建 ${ }^{[12-16]} .2017$ 年, Werz 课题组 ${ }^{[17]}$ 报道了一 种镁催化 D-A 环丙烷 8 和 1,3,5-三嗪烷 1 合成 2-取代吡
咯烷 9 的方法(Scheme 3-1). 反应中使用的碘化镁催化 剂既作为 Lewis 酸, 促进 D-A 环丙烷开环，又可以提供 碘离子，作为后续反应的离去基团. 在相同条件下，延 长反应时间, 1,3,5-三嗪烷还能与 D-A 环丁烷 $\mathbf{1 0}$ 进行 $[2+4]$ 环加成反应, 生成哌啶类衍生物 11 (Scheme 3-2). 作者只研究了苯基以及对甲氧基苯基取代 D-A 环丁烷 的反应情况，反应结果表明，对甲氧基苯基取代环丁烷 的产率(67\% 75\%)要优于苯基取代环丁烷(56\%).

2018 年, 刘吉开团队 ${ }^{[18]}$ 采用相同的反应策略, 发展 了一种铝催化 D-A 环丙烷 12 与 1,3,5-三嗪烷合成 2-取 代吡咯烷 13 的方法(Scheme 4). 作者只探讨了芳基环丙 烷的反应结果, 在底物适应性方面要比 Werz 课题组 ${ }^{[17]}$ 更局限一些.

第二年, 刘吉开团队 ${ }^{[19]}$ 发展了一种锌催化氮杂环 丙烷合成咪唑啉的方法(Scheme 5). 作者采用氮杂环丙 烷 14 作为 1,3-偶极子，与 1,3,5-三嗪烷提供的甲酰基亚 胺, 发生 $[2+3]$ 环加成反应, 合成一系列咪唑啉衍生物 

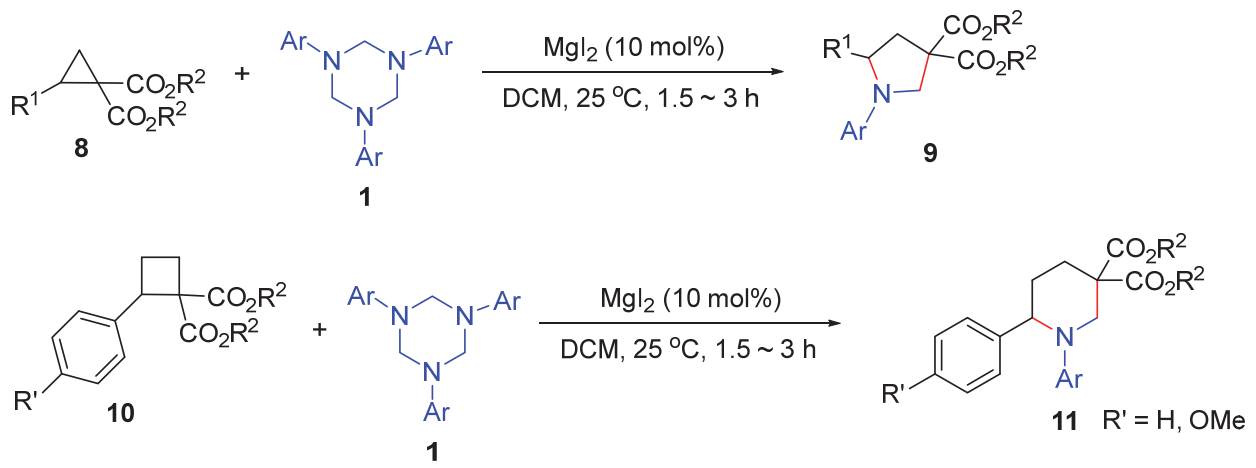

图式 3 镁催化 1,3,5-三嗪烷 $[2+3]$ 或 $[2+4]$ 环加成

Scheme 3 Mg-catalyzed [2+3] or [2+4] cycloaddition of 1,3,5-triazinanes

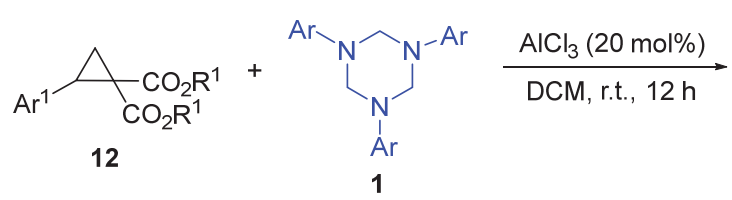<smiles>[R17]OC(=O)C1(C(=O)O)CC([Al])N(Br)C1</smiles>

13: $50 \% \sim 99 \%$ yields

图式 4 铝催化 1,3,5-三嗪烷[2+3]环加成

Scheme 4 Al-catalyzed [2+3] cycloaddition of 1,3,5-triazinanes

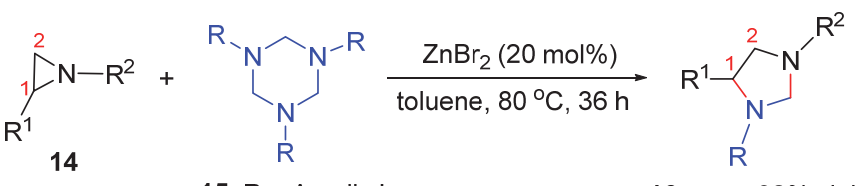

15: $R=A r$, alkyl 16: up to $92 \%$ yield

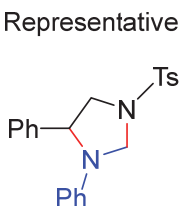

16a: $80 \%$<smiles>[NH3+]C1CN(CC(Cl)(Cl)Cl)CC1c1ccccc1</smiles>

16b: $92 \%$<smiles>Pc1ccccc1</smiles>

16c: $36 \%$<smiles>C=CC1CN([Al-])CN1c1ccccc1</smiles>

16d: $79 \%$

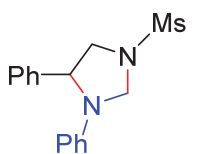

16e: $83 \%$<smiles>c1ccc(CN2CC(c3ccccc3)N(c3ccccc3)C2)cc1</smiles>

16f: $76 \%$

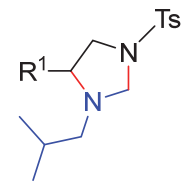

$16 \mathrm{~g}: 60 \%$

图式 5 锌催化 1,3,5-三嗪烷[2+3]环加成

Scheme 5 Zn-catalyzed [2+3] cycloaddition of 1,3,5-triazinanes

16. 在该反应中, 澳化锌促进氮杂环丙烷 $\mathrm{C}_{1}-\mathrm{N}$ 键断裂. 值得一提的是，除了芳基取代的三嗪烷外，烷基取代的 三嗪烷也能顺利参与反应，以较高的收率得到相应的目 标产物.

2021 年, 蒋宇扬等 ${ }^{[20]}$ 报道了一种钎催化氮杂环丙 烷合成咪唑啉的方法(Scheme 6). 该方法采用活性更高 的 D-A 氮杂环丙烷 17 为原料, 在温和的条件下就能快 速构建咪唑啉目标产物 18. 由于两个酯基的作用, 氮杂 环丙烷在 $\mathrm{C}(1)-\mathrm{C}(2)$ 处发生断键, 这一点和刘吉开等 ${ }^{[19]}$ 的工作不同. 考虑到咪唑啉骨架在药物化学中的重要 性, 作者随机选择了部分由该方法合成的咪唑啉产物, 用于评估人类不同癌细胞系中的抗增殖活性, 初步结果 表明, 这些咪唑啉类化合物对人类许多癌细胞显示出有 希望的抗肿瘤活性，可作为抗肿瘤研究的热门化合物.

翟宏斌等 ${ }^{[21]}$ 报道了一种铟催化环己二烯酮 19 合成

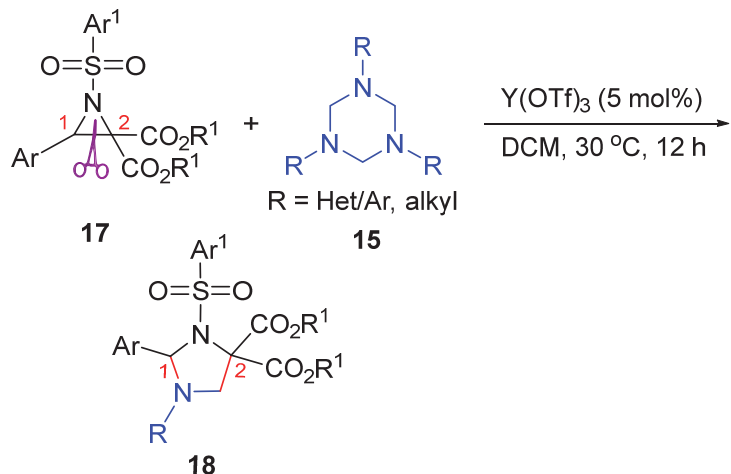

图式 6 钎催化 1,3,5-三嗪烷[2+3]环加成

Scheme 6 Y-catalyzed [2+3] cycloaddition of 1,3,5-triazinanes 咪唑啉化合物的方法(Scheme 7). 该方法采用三氟甲磺 酸铟为催化剂, 二氯甲烷为溶剂, $50{ }^{\circ} \mathrm{C}$ 条件下合成一系 列环己烯酮并咪唑啉衍生物 20. 在相同反应条件下, 差弪 
基取代的反应物也能兼容, 以较高收率合成噁唑啉衍生 物.

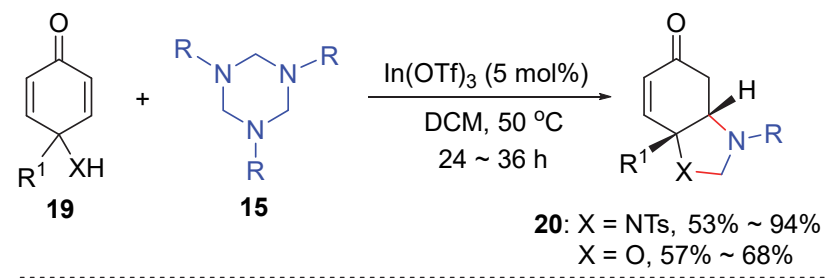

Representative products 20a: $84 \%$

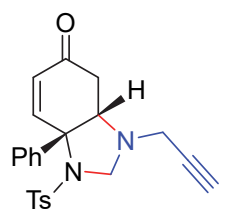

20d: $54 \%$

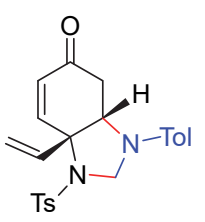

20g: $82 \%$

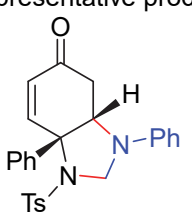

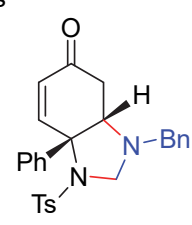

20b: $73 \%$

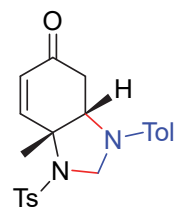

20e: $90 \%$

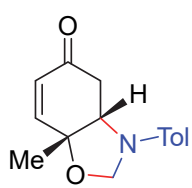

20h: $68 \%$
图式 7 铟催化 1,3,5-三嗪烷[2+3]环加成

Scheme 7 In-catalyzed [2+3] cycloaddition of 1,3,5-triazinanes

孙江涛等 ${ }^{[22]}$ 报道了一种碱促进合成咪唑啉酮的方 法(Scheme 8). 该方法不需要使用过渡金属催化剂, 反 应过程中, 现场产生氮杂烯丙基正离子 23 和甲酰基苯 基亚胺 24 两种活性中间体，这两种中间体随后进行分 子间 $[2+3]$ 环加成反应, 一锅法合成咪唑啉酮衍生物. 反应只能在六氟异丙醇中进行, 对于其它溶剂(二氯甲 烷、甲苯、1,4-二氧六环等)几乎检测不到产物. 除了溴
代底物，氯代底物也能发生反应，但收率略低(31\%).

袁伟成等[23]报道了一种有机催化异硫氰 25 与三嗪 烷合成螺咪唑并吲哚啉 26 的反应(Scheme 9). 该反应采 用手性硫脲催化剂, 通过现场产生的甲酰基亚胺和异硫 氰酸根发生曼尼希/分子内环化串联过程, 实现螺环化 合物的不对称合成. 值得注意的是，这是 1,3,5-三嗪烷 第一个有机催化不对称反应. 在该反应中, 对于茮基取 代的三嗪烷，尽管产率没有影响, 但是 ee 值急剧下降 $(34 \%$ ee $)$.

孙江涛课题组 ${ }^{[24]}$ 报道了一种铜催化三嗪烷合成六 氢苯并喹唑啉的方法(Scheme 10). 采用一价铜为催化 剂, 和手性噁唑啉配体共同作用, 参与完成六氢苯并喹 唑啉衍生物 28 的不对称合成. 机理研究表明, 在该反应 中产生了两种两亲性偶极中间体，也就是丙二烯铜复合 物 29 和甲酰基亚胺 24, 随后二者发生[4+2]环加成过 程. 采用 $N$-烷基取代三嗪烷时, 能以较高的产率和 $e e$ 值 得到相应的苯并喹唑啉衍生物, 突破了以往 $N$-烷基取 代三嗪烷环化反应产率低的局限. 在相同的反应条件 下，使用其它亚胺也能反应，但会产生两种难以分离的 异构体，并且这两种异构体都不稳定.

2019 年, 刘吉开课题组 ${ }^{[25]}$ 报道了一种温和的无金 属催化剂作用的逆电子环化反应(Scheme 11). 此反应 中, 茮基氯 31 在碳酸钠作用下现场产生邻位氮杂苯醌 活性中间体，该中间体随后被甲酰基亚胺捕获，快速高 效地构建了一系列四氢喹唑啉骨架 32. 三嗪烷的位阻 效应对产率的影响较大，值得注意的是，该环加成反应 代表了 $1,3,5$-三嗪烷的逆电子 $[4+2]$ 环加成反应的首个 例子. 反应放大至克级规模时, 产率完全没有影响.

2020 年，肖文精等 ${ }^{[26]}$ 报道了一种光催化合成多氟 烷基取代四氢喹唑啉 35 的方法(Scheme 12). 反应的关 键是：(1)邻烯基苯胺 33 和多氟烷基自由基前体在光催 化下自由基加成的过程中，顺利产生邻亚甲基氮杂苯醌 中间体；(2) 1,3,5-三嗪烷产生甲酰基亚胺中间体. 与刘 吉开课题组 ${ }^{[21]}$ 相比，该方法具有反应时间短，底物适用

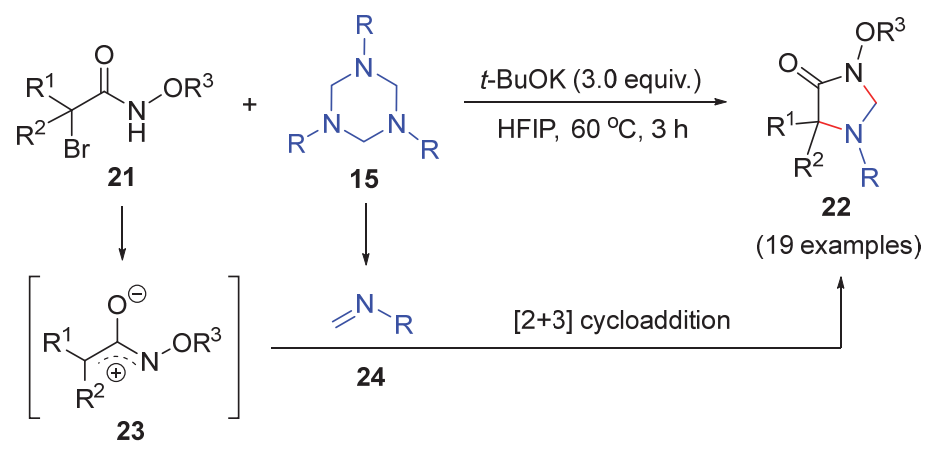

图式 8 碱促进羟肜酸醚与 1,3,5-三嗪烷[2+3]环加成

Scheme 8 Base-promoted [2+3] cycloaddition of 1,3,5-triazinanes with hydroxamate 
<smiles>CN1C(=O)C([N+](=O)[O-])c2ccccc21</smiles><smiles>[R]N1CN([R])CN([R])C1</smiles>

15

$\mathrm{R}=\mathrm{Ar}, \mathrm{Bn}$

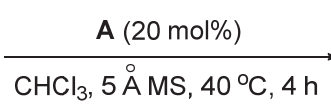

$\mathrm{CHCl}_{3}, 5 \AA \mathrm{A} \mathrm{MS}, 40^{\circ} \mathrm{C}, 4 \mathrm{~h}$<smiles>[R]N1CC2(CN1)C(=O)N([R])c1ccccc12</smiles>

26

up to $99 \%$ yield, $93 \%$ ee

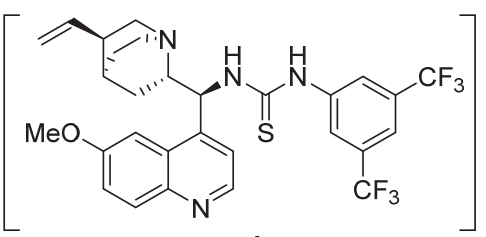

A

图式 9 有机催化 1,3,5-三嗪烷[2+3]不对称环加成

Scheme 9 Organocatalytic asymmetric [2+3] cycloaddition of 1,3,5-triazinanes
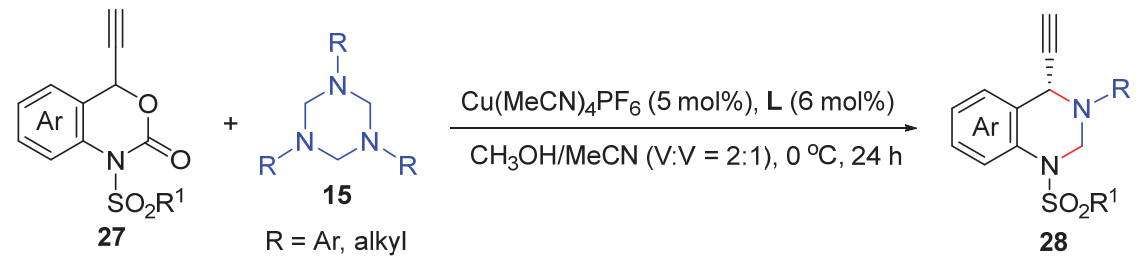

ee up to $98 \%$ (20 examples)
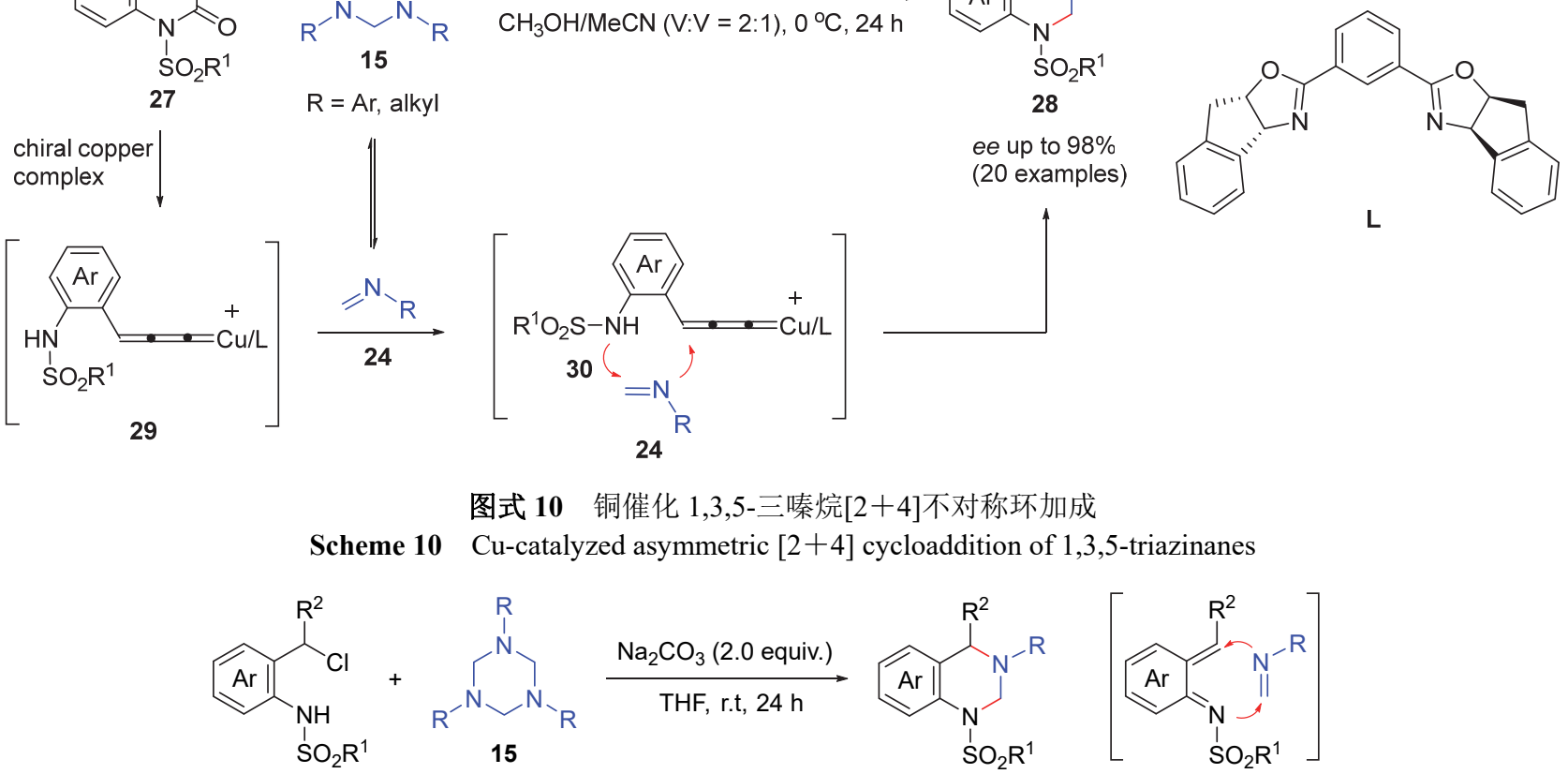

图式 10 铜催化 1,3,5-三嗪烷 [2+4]不对称环加成

Scheme 10 Cu-catalyzed asymmetric [2+4] cycloaddition of 1,3,5-triazinanes<smiles>[R]C(Cl)c1ccccc1NS([R20])(=O)=O</smiles>

31<smiles>[R]N1CN([R])CN(P)C1</smiles>

15 $\frac{\mathrm{Na}_{2} \mathrm{CO}_{3}(2.0 \text { equiv. })}{\text { THF, r.t, } 24 \mathrm{~h}}$

Representative products<smiles>Cc1ccc(N2Cc3ccccc3N(C)C2)cc1</smiles>

32a: $88 \%$

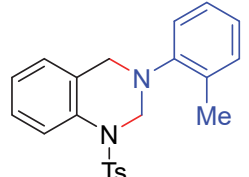

32b: $25 \%$<smiles>[Y]N1CN(c2ccccc2Br)Cc2ccccc21</smiles>

32c: $54 \%$

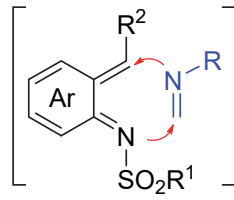

图式 11 1,3,5-三嗪烷逆电子[2+4]环加成

Scheme 11 Inverse-electron-demand [2+4] cycloaddition of 1,3,5-triazinanes<smiles>[R]N1CN([R])CN([R])C1</smiles>

33

15

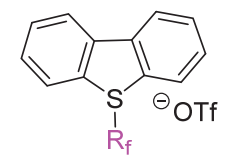

34

$$
\begin{aligned}
& \underset{\text { fac-[Ir(ppy } \left.)_{3}\right](2 \text { mol\% })}{\mathrm{Na}_{2} \mathrm{HPO}_{4}(2.0 \text { equiv. })} \\
& \begin{array}{c}
7 \mathrm{~W} \text { blue LEDs } \\
\text { DCM, r.t., } 5 \mathrm{~h}
\end{array}
\end{aligned}
$$<smiles>[R]CC1c2ccccc2N(S(=O)(=O)O)CN1[R]</smiles>

35

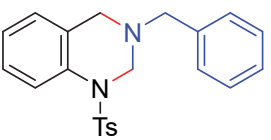

32d: $99 \%$

图式 12 光氧化还原催化自由基介导的氮杂邻苯醌的生成和 $[2+4]$ 环加成

Scheme 12 Photoredox-catalyzed radical-mediated formation of aza- $o$-QMs and $[2+4]$ cycloadditions

范围广等优点.

同年，宣俊等 ${ }^{27]}$ 报道了一种合成 1,3-苯并啞嗪衍生 物的方法(Scheme 13). 反应无需添加过渡金属催化剂、
碱以及配体，只需将对亚甲基苯醌 36 和三嗪烷 15 的二 氯甲烷溶液加热即可. 有意思的是，位阻效应对反应结 果几乎没有影响. 利用该策略，成功实现了对薄荷醇、 
非诺贝特、氯雷他定等活性药物分子的修饰. 当前的反 应体系还可以进一步扩展到四氢喹唑啉衍生物的构建 中.<smiles>[R]C1=CC(=Cc2ccccc2[Y])C=C([R])C1=O</smiles>

36<smiles>[R]N1CN([R])CN([R])C1</smiles>

15<smiles>[R]C1=CC2=CC([R])=C(OC1[R])C2c1ccccc1[X]</smiles>

37: $X=O, N T s$
图式 13 亚甲基对苯醌与 1,3,5-三嗪烷 [2+4]环加成 Scheme $13[2+4]$ cycloaddition of para-quinone methides with 1,3,5-triazinanes

翟宏斌课题组 ${ }^{[28]}$ 发展了一种合成苯并呋喃并嘧啶 衍生物的方法(Scheme 14). 反应以 $\alpha, \beta$-不饱和亚胺 38 为原料, 在加热条件下直接和三嗪产生的甲酰基亚胺进 行 $N$-迈克尔加成 $/ N$-曼尼希反应的分步或者协同过程, 得到一系列苯并呋喃并嘧啶类骨架 39. 该方法同样适 用于其它类似的不饱和亚胺中, 构建相应的嘧啶类衍生 物.<smiles>[R]C=C1Oc2ccccc2C1=N[R1]</smiles>

39a: $66 \%$

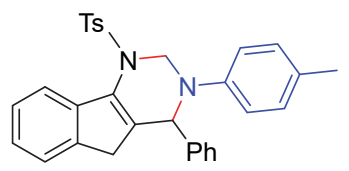

39b: $59 \%$

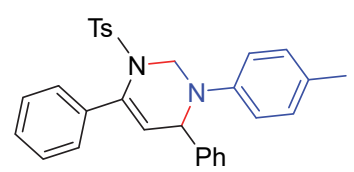

39c: $42 \%$

图式 $14 \alpha, \beta$-不饱和亚胺与 $1,3,5$-三嗪烷 $[2+4]$ 环加成 Scheme $14[2+4]$ cycloaddition of 1,3,5-triazinanes and $\alpha, \beta$ unsaturated imines

2021 年, 宣俊课题组 ${ }^{[29]}$ 报道了一种光催化 $\alpha$-重氮 酸酯合成氮杂环丙烷的方法(图示 15). 值得注意的是, 该反应仅在可见光照射下发生, 无需添加光氧化还原催 化剂. 并且氮气是该反应唯一的副产物, 对环境无污染.

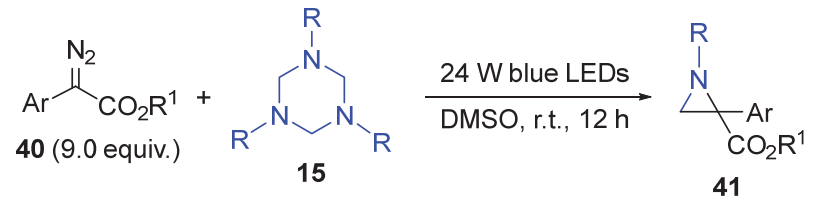

图式 15 可见光促进 $\alpha$-重氮酸酯与 1,3,5-三嗪烷 $[2+1]$ 环加成 Scheme 15 Visible light-promoted [2+1] cycloaddition of 1,3, 5 -triazinanes and $\alpha$-diazo esters

\section{2 作为三原子合成子}

2018 年, 杨伟波等 ${ }^{[30]}$ 报道了利用钯催化碳酸乙烯 酯 42 (VECs) 多样性合成氮杂环的反应(Scheme 16). VECs 在钯催化的协助下脱除 $\mathrm{CO}_{2}$, 产生的烯丙基钯是 该反应的重要中间体. 选择烯丙基氯化钯为催化剂, 二 氯甲烷作为溶剂时，1,3,5-三嗪烷作为双原子合成子和 碳酸乙烯酯进行 $[2+5]$ 环加成反应, 得到七元含氮杂环 骨架 43; 而将催化剂换成环辛二烯氯化钯，调整反应溶 剂则按照 $[3+2]$ 环化反应模式进行, 以更好的收率生成 一系列五元含氮杂环衍生物 44. 此时, 三嗪烷作为 $\mathrm{N}-$ $\mathrm{C}-\mathrm{N}$ 三原子合成子.
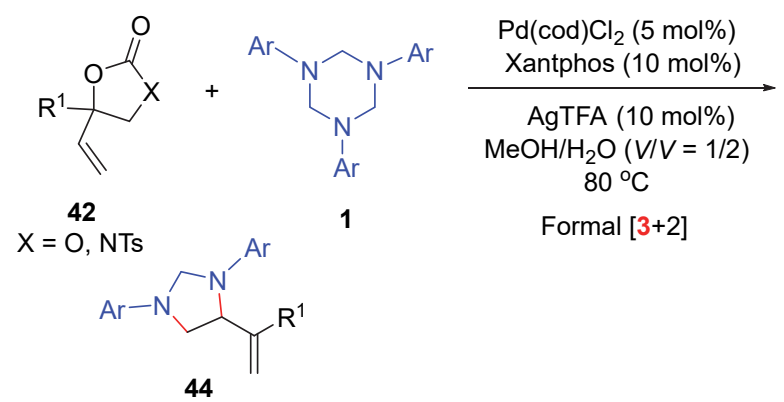

$$
26 \% \sim 96 \% \text { yields }
$$

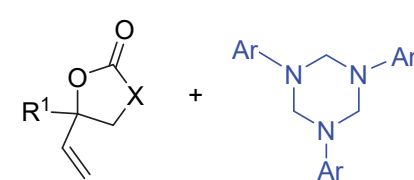

42

$\mathrm{X}=\mathrm{O}, \mathrm{NTs}$

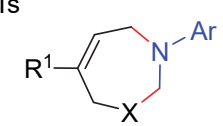

43

$33 \% \sim 85 \%$ yields

图式 16 钯催化碳酸乙烯酯可控环化反应

Scheme 16 Pd-catalyzed controllable cyclization of vinylethylene carbonates

次年，杨伟波课题组 ${ }^{[31]}$ 在前期工作基础上，通过分 步操作合成了四氢嘧啶骨架 47 (Scheme 18). 首先钯催 化剂对碳酸乙烯酯 45 作用 $2 \mathrm{~h}$ ，除去二氯甲烷后，向反 应体系内加入甲醇和水的混合溶剂以及 $1,3,5$-三嗪烷, 继续反应 $2 \mathrm{~h}$. 与之前报道的碳酸乙烯酯作为三原 


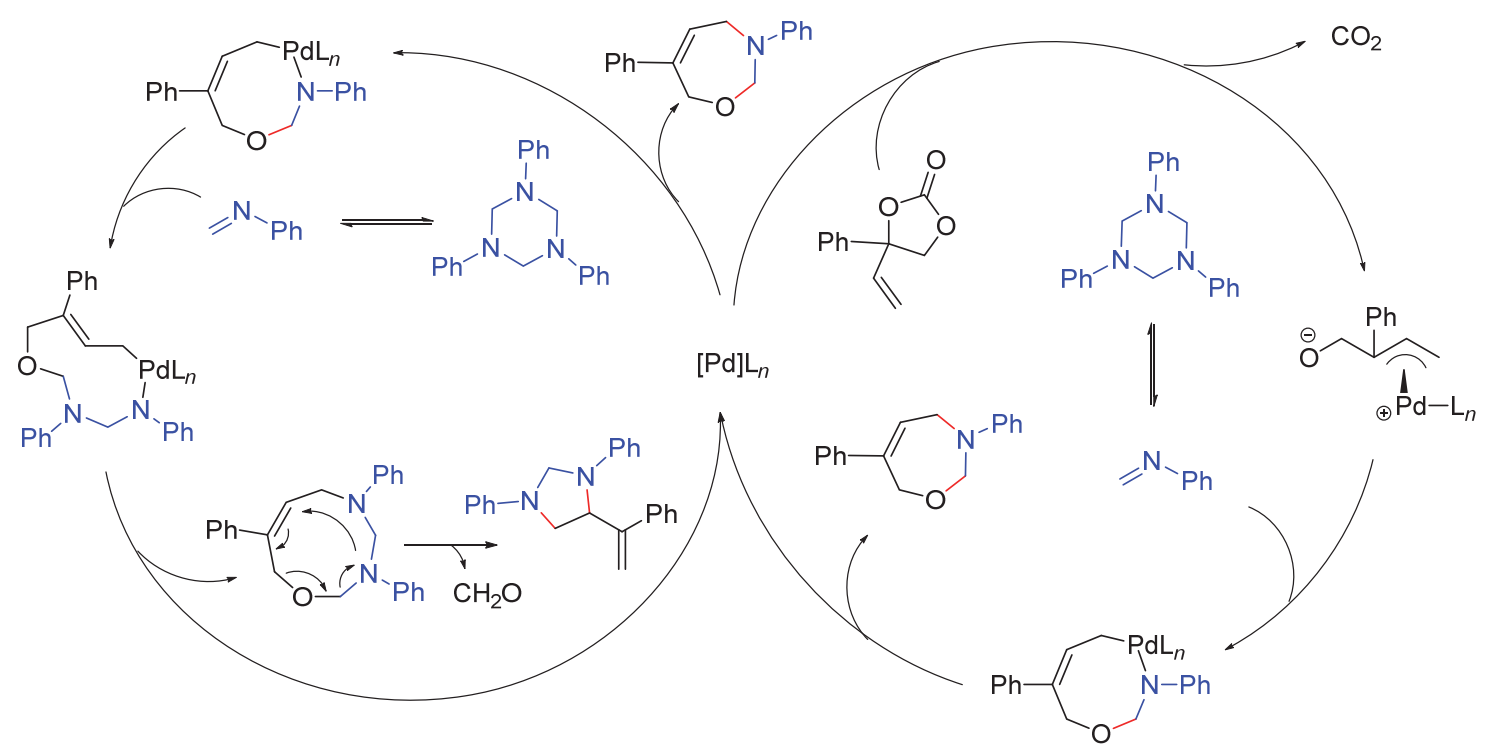

图式 17 钯催化碳酸乙烯酯环化反应机理

Scheme 17 Possible mechanism of Pd-catalyzed cyclization of vinylethylene carbonates

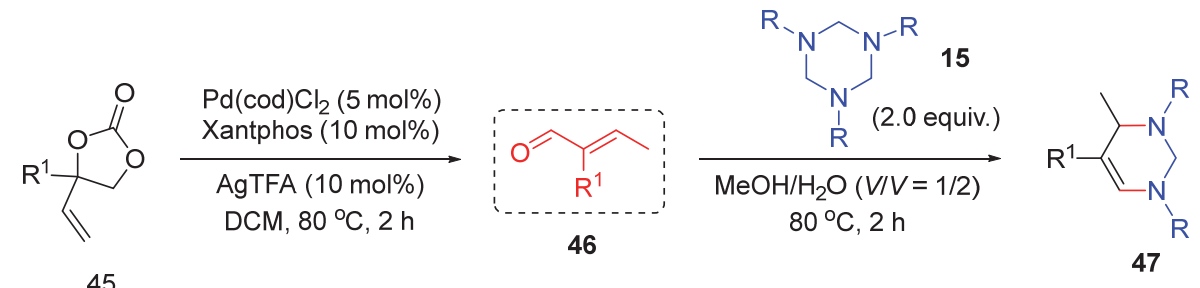

图式 18 碳酸乙烯酯分步 $[3+3]$ 环加成

Scheme 18 [3+3] step-wise cycloadditions of vinylethylene carbonates

子 ${ }^{[32,33]}$ 或者五原子 ${ }^{[34-37]}$ 合成子的情况不同，该机理研究 表明, 碳酸乙烯酯通过钯催化脱 $\mathrm{CO}_{2}$ 和 $\beta-\mathrm{H}$ 消除的组合 过程, 生成的 $\alpha, \beta$-不饱和醛 46 作为三个碳合成子进行环 加成反应. 在合成四氢嘧啶骨架过程中, 三嗪烷提供 $\mathrm{N}-\mathrm{C}-\mathrm{N}$ 三原子合成子.

孙江涛等 ${ }^{[38]}$ 报道了一种无金属催化剂作用下合成 多取代嘧啶骨架的方法(Scheme 19). 该方法采用亚胺 48 和三嗪烷为反应底物, 操作简单方便, 反应对环境友 好. 在此 $[3+3]$ 环加成反应中, 首次将 $1,3,5$-三嗪烷用作 1,3-偶极子(提供 $\mathrm{C}-\mathrm{N}-\mathrm{C}$ 片段). 机理研究表明, 反应 是一个分步过程, 即亚胺首先和三嗪烷原位产生的甲酰 基亚胺反应，随后和甲醛进行缩合，得到最终的嘧啶衍 生物 52 .

翟宏斌等 ${ }^{[39}$ 报道了一种 $\alpha$-烯醇取代二硫酯 $\mathbf{5 3}$ 参与 合成四氢噻嗪 56 的方法(Scheme 20). 三嗪烷通过甲醛 亚胺和甲醛先后与底物 53 反应, 提供 $\mathrm{C}-\mathrm{N}-\mathrm{C}$ 片段. 值得一提的是, 位阻对反应产率几乎没有影响, 并且 $N$ 芳基取代的三嗪烷具有更好的反应效果, 换成 $N$-烷基 取代的三嗪烷(环丙基)时，产率下降至 50\%.

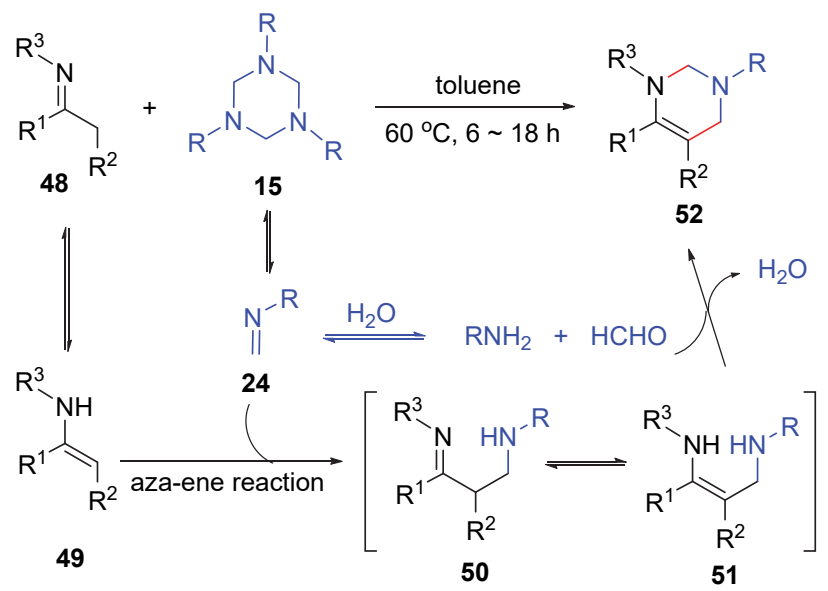

图式 19 亚胺与 $1,3,5$-三嗪烷[3+3]环加成

Scheme 19 [3+3] cycloaddition of imines with 1,3,5-triazinanes

\section{3 作为四原子合成子}

过渡金属催化羰基重氮化物前体与偶极加合物的 环加成反应，是快速构建各种复杂骨架的有力工具，并 且重氮化合物可用作 1 至 3 个碳的合成子，参与各种

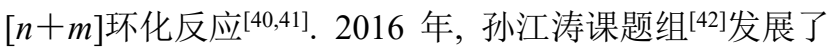




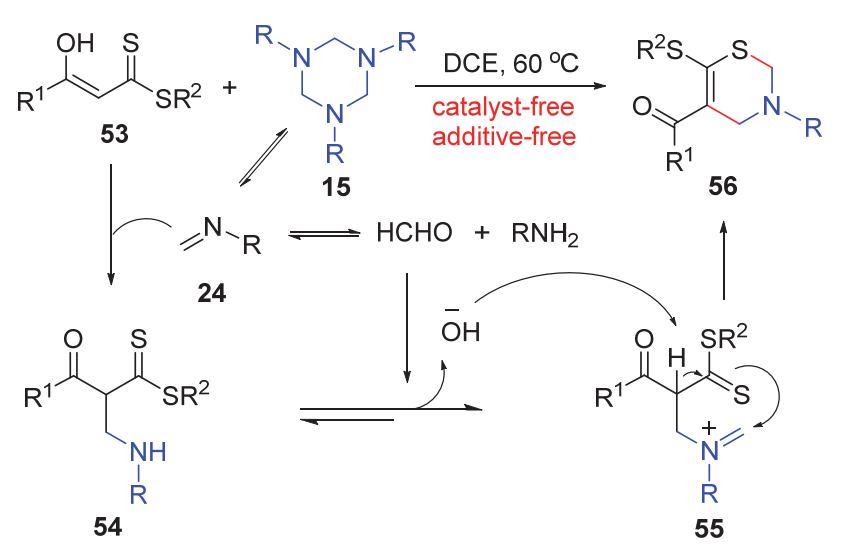

图式 $20 \alpha$-烯醇二硫酯与 1,3,5-三嗪烷 [3+3]环加成 Scheme $20[3+3]$ cycloaddition of $\alpha$-enolic dithioesters and 1,3,5-triazinanes

金催化重氮羧酸酯合成五元或七元含氮杂环的方法 (Scheme 21). 该策略是首次使用不同的重氮底物, 特别 是烯醇重氮化合物进行金催化 $[4+1] /[4+3]$ 环加成反应 的例子. 这也是首次将稳定的三嗪烷作为偶极加合物, 用于涉及卡宾的环加成反应当中. 机理研究实验表明, 在反应过程中, 三溙烷无需转变成甲酰基亚胺, 而是直 接参与反应(Scheme 22).

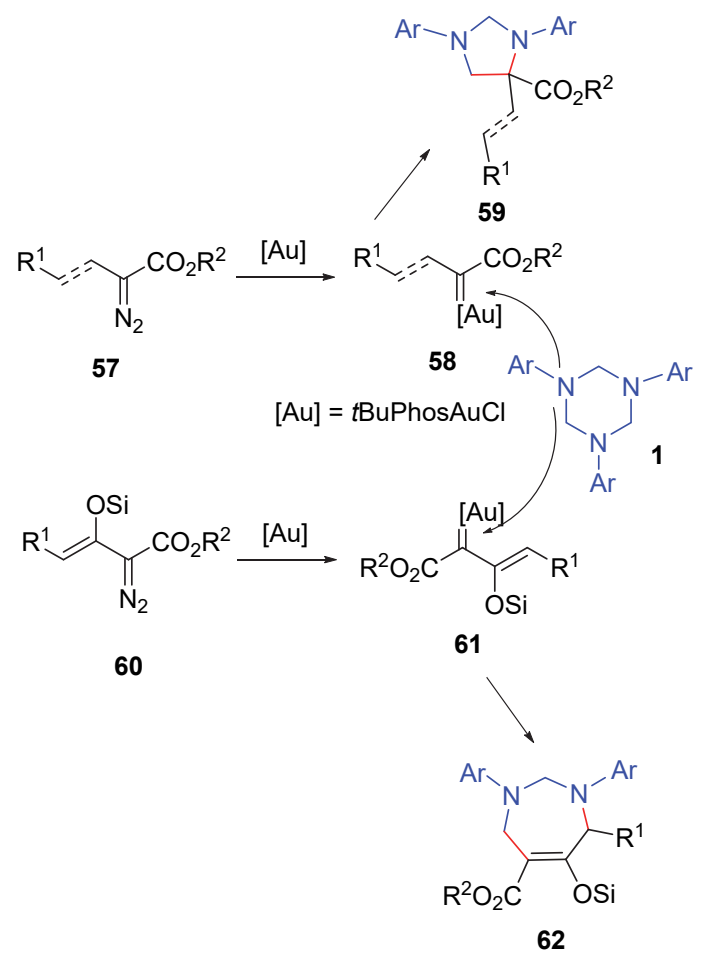

图式 21 金催化 1,3,5-三嗪烷与重氮化合物环加成 Scheme 21 Gold-catalyzed formal $[4+1] /[4+3]$ cycloadditions of 1,3,5-triazinanes with diazo compounds

2017 年, 孙江涛课题组 ${ }^{[43]}$ 研究了碱促进腙和 1,3,5三嗪烷的反应(Scheme 23). 在该反应中, 腙 70 作为重 氮化合物前体, 与三嗪烷原位生成的甲酰基亚胺进行

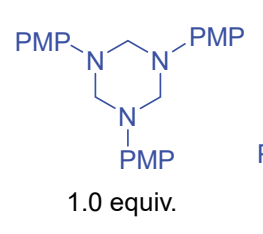

63<smiles>COC1(c2ccccc2)CN(c2ccccc2)CN1c1ccccc1</smiles><smiles>COC(=O)C1(c2ccccc2)CN(c2ccccc2)CN1PN</smiles>

68: $0 \%$<smiles>O=C(O)N1CN(c2ccccc2)C[NH+](c2ccccc2)C1</smiles>

64
${ }^{t} \mathrm{BuPhosAuCl}$ (5 mol\%)

THF, $60^{\circ} \mathrm{C}$ $12 \mathrm{~h}$
65
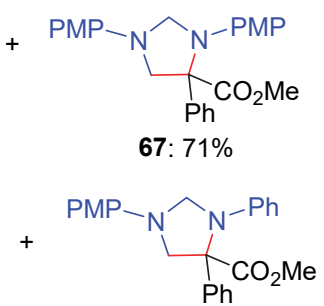

69: $0 \%$

图式 22 金催化 $[4+1$ ] 环加成交叉实验

Scheme 22 Cross-over experiment of gold-catalyzed formal $[4+1]$ cycloadditions

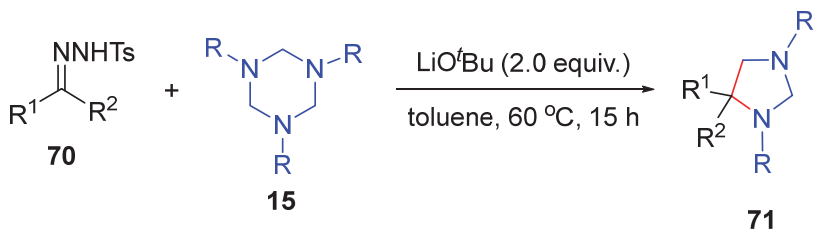

图式 23 叔丁基锂促进三嗪烷与苯腙的 [4+1]环加成 Scheme 23 Tert-butyllithium-promoted [4+1] cycloaddition of triazinanes with phenylhydrazone

$[1+4]$ 环加成反应. 需要指出的是, 叔丁醇钾起着双重 作用: (1)促进腙转化成 Donor-Donor 重氮, (2)促进 $[1+4]$ 环加成过程. 也可通过羰基化合物与对甲苯磺酰朋肤 应，现场制备相应的腙类化合物，反应产物无需分离， 直接进行下一步的环加成反应, 以较好的收率得到相应 的咪唑啉衍生物 71, 避免了中间体的提取纯化, 简化了 实验操作步骤，提高了合成效率，减少了副产物的产生.

随后，该课题组 ${ }^{[4]}$ 又发展了铁催化合成咪唑啉的 反应(Scheme 24). 通过铁催化剂作用, 一步实现 $\mathrm{C}-\mathrm{C}$ 键和 $\mathrm{C}-\mathrm{N}$ 键的构建. 重要的是，与金催化 ${ }^{[42]}$ 体系不同, Donor-Donor 和 Donor-Accepor 重氮化合物都能在铁催 化体系兼容, 并且这两种重氮化合物可由游离腙以及对 甲苯磺酰腙通过简单的操作制备, 这在一定程度上拓宽 了重氮化合物在环化反应中的使用范围.

2019 年, 王彦广和吕萍课题组 ${ }^{[45]}$ 报道了一种铜(I) 催化合成螺吲哚咪唑啉 77 的方法(Scheme 25). 吲哚啉 重氮 76 在铜催化剂作用下, 脱除一分子氮气产生铜卡 宾重要中间体, 随后与三嗪烷进行 $[2+2+1]$ 环加成反 应. 只是该策略的产物产率整体偏低, 并且由于底物的 特殊性，限制了该方法的使用.

2021 年, 宣俊课题组 ${ }^{[29]}$ 报道了光促进 $\alpha$-重氮酸酯 合成咪唑啉化合物的反应(Scheme 26). 反应条件与 $[2+$ 


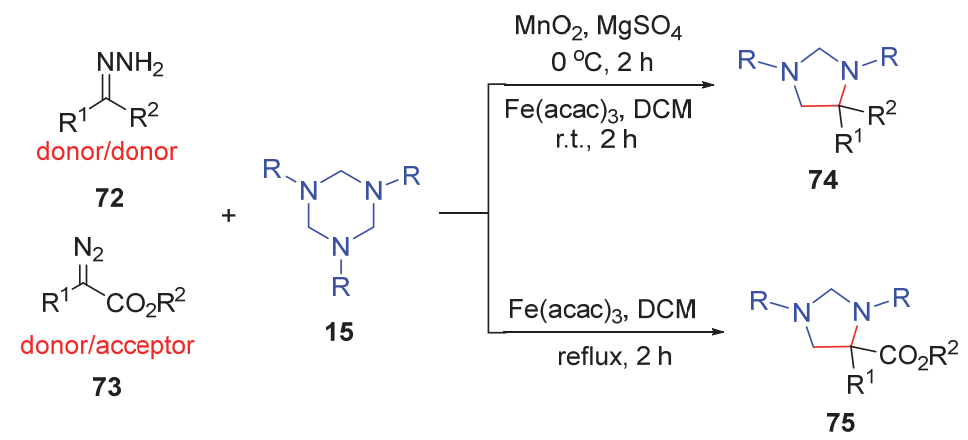

图式 24 铁催化 1,3,5-三嗪烷与重氮/重氮类似物的 $[4+1$ ] 环加成

Scheme 24 Fe-catalyzed [4+1] cycloadditions of 1,3,5-triazinanes with diazo or diazo analogues<smiles>[R7]N(C)S([R])(=O)=NC1C(=N)c2ccccc2N1C</smiles>

76<smiles>[Al]N1CCCN([Al])C1</smiles>

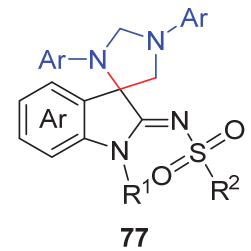

77

图式 25 铜催化吲哚重氮与三嗪烷的 $[4+1]$ 环加成

Scheme $25 \mathrm{Cu}$-catalyzed [4+1] cycloadditions of triazinanes with indole diazo compounds

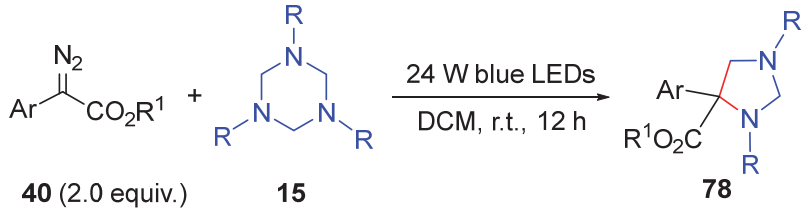

图式 26 可见光促进 $\alpha$-重氮酸酯与 1,3,5-三嗪烷 [4+1]环加成 Scheme 26 Visible light-promoted [4+1] cycloaddition of 1,3, 5 -triazinanes and $\alpha$-diazo esters

1]环化反应(Scheme 15)类似, 不同的是将反应介质由二 甲基亚砜换成二氯甲烷，同时调整 $\alpha$-重氮酸酯和 $1,3,5-$ 三嗪烷的比例, 即可发生 $[4+1]$ 环加成过程, 生成一系 列咪唑啉衍生物 78.

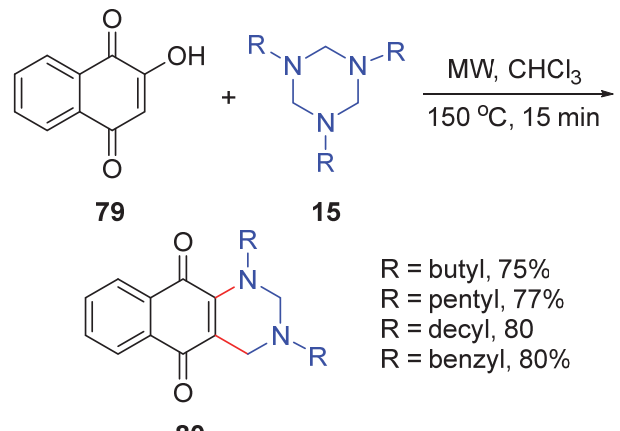

图式 27 微波促进三嗪烷合成六氢嘧啶并 1,4-芸醌 Scheme 27 Microwave-promoted synthesis of hexahydropyrimidine-fused 1,4-naphthoquinones from triazinanes

Ferreira 等 ${ }^{[46]}$ 报道了微波照射作用下, 利用指甲花
醌 79 (Lawsone)和三嗪烷合成芸醌并嘧啶骨架 80 的方 法(Scheme 27). 该方法反应时间短, 能快速高效地构建 含多种取代基的萗醌并嘧啶衍生物.

2017 年，孙江涛等 ${ }^{[47]}$ 报道了一种金催化联烯合成 嘧啶衍生物的方法(Scheme 28). 由于底物取代基的不 同，参与成环的 $\mathrm{C}=\mathrm{C}$ 键也不同. 对于联烯胺底物 $\mathbf{8 1}$, 金催化剂倾向于和双键结合，三嗪烷原位产生的甲酰基 亚胺则进攻 $\mathrm{C} 1$ 端，将底物换成联烯酯 82, 由于金催化 剂更倾向于和氧原子结合，甲酰基亚胺则进攻 C2 端, 因而影响了产物中双键所在的位置.

作为炔烃化学的重要分支之一, 炔胺化合物是一类 富电子炔烃, 由于炔胺的内在极化原因, 使炔胺在环化 反应中具有高度区域选择性和立体选择性 [48-51]. 2017 年, Hashmi 课题组 $\left.{ }^{[52}\right]$ 报道了一种金催化炔胺 85 合成四 氢嘧啶 90 的方法(Scheme 29). 该课题组首次实现了炔 胺与无张力杂环的环化过程. 该方法具有易操作，起始 原料易获得，1,3,5-三嗪烷作为稳定的四原子构建单元， 官能团耐受性广以及扩大规模反应的潜力等优点，使该 新方案具有吸引力和实用性. 初步的机理研究表明, 反 应经历了分子间 $[2+2+2]$ 环化过程，完成炔胺的碳胺 环化过程.

同年, Werz 等 ${ }^{[53]}$ 发展了由 Donor-Acceptor 环丙烷 8 和 1,3,5-三嗪烷构建 1,3-高哌嗪骨架 91 的反应(Scheme 30). 反应采用三氟甲磺酸铊(III)作为有效催化剂, 促进 D-A 环丙烷与三嗪烷的 $[3+4]$ 环加成反应. 对产物进行 简单的酸化处理，便可得到 1,4-二胺化合物 92, 从形式 
<smiles>[R]C=CN([R])C</smiles><smiles>[R]C=CC=CC(=O)O[Na]</smiles>

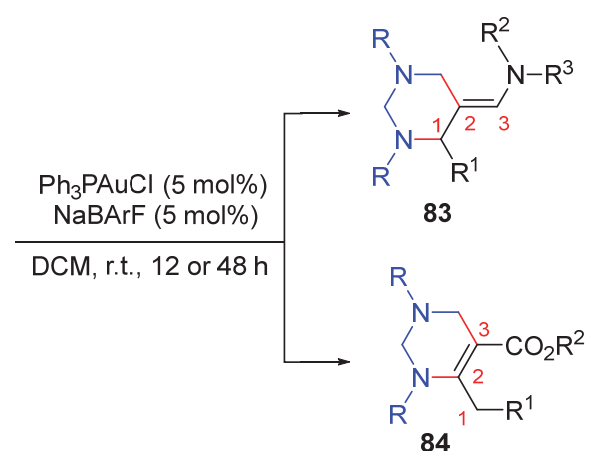

图式 28 金催化联烯与三嗪烷多样性[4+2]环加成

Scheme 28 Gold-catalyzed regiodivergent [4+2] cycloadditions of allenes with triazinanes

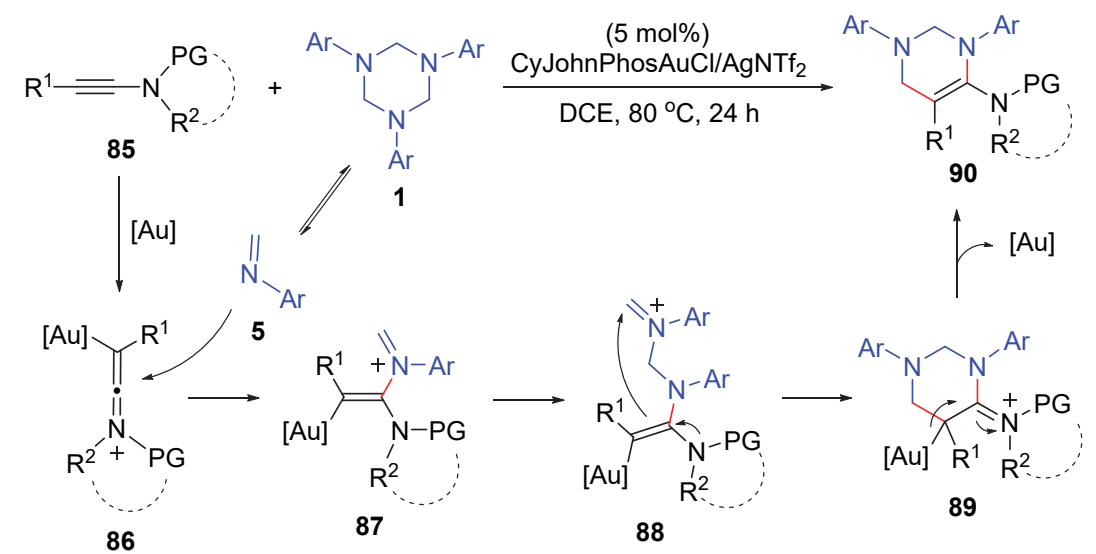

图式 29 金催化炔胺与三嗪烷[4+2]环加成

Scheme 29 Gold-catalyzed [4+2] cycloadditions of ynamides with triazinanes

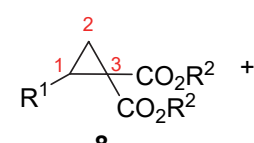

8

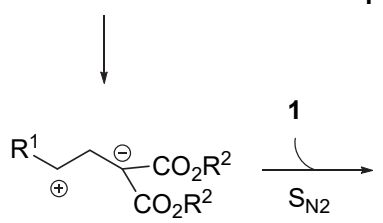

93

1

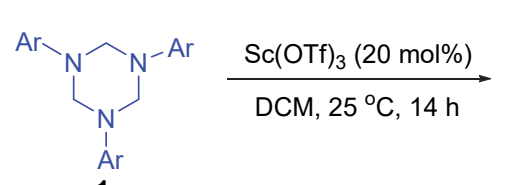

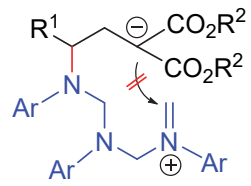

94

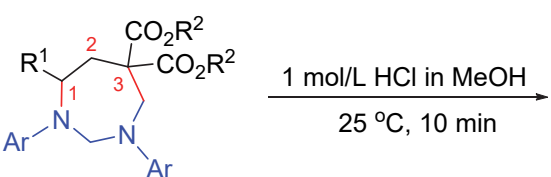

91

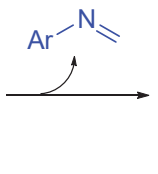

$\longrightarrow \mathrm{Ar}_{\oplus}^{-\mathrm{N}} \mathrm{CO}_{\mathrm{Ar}}^{\mathrm{CO}_{2} \mathrm{R}^{2} \mathrm{R}^{2}}$

95

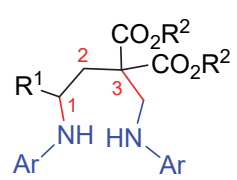

92

图式 30 推-拉环丙烷开环 1-氨基-3-胺甲基化

Scheme 30 Ring-opening 1-amino-3-aminomethylation of donor-acceptor cyclopropanes

上, 炔烯酮化合物 96 在金属催化剂作用下产生 1,3-偶极 子中间体 97, 该中间体能与烯烃、硝酮等进行 $[3+n]$ 环 加成反应, 构建多元碳环及杂环骨架 ${ }^{[54-60] .2017}$ 年, 孙 江涛 ${ }^{[61]}$ 和徐新芳 ${ }^{[2]}$ 课题组先后报道了金催化炔烯酮和 1,3,5-三嗪烷的反应(Scheme 31). 在金催化剂作用下, 炔烯酮与三嗪烷原位产生的甲酰基亚胺进行反应, 快速 构建 1,3-高哌嗪并呋喃骨架 98. 他们认为, 反应经历了 逐步的 $[3+2+2]$ 环化过程; 该策略操作简便, 反应温
和, 为全取代呋喃的合成提供了新思路.

\section{4 其它}

四氮杂环骨架代表了重要的且有吸引力的一类七 元氮杂环骨架, 它们在药物和农药化学中具有重要的生 物学特性 ${ }^{[62,63]} .2021$ 年, 王凯凯等 ${ }^{[64]}$ 报道了无金属催化 合成四氮杂草 103 的反应(Scheme 32). 亚胺叶立德 99 和 $1,3,5$-三嗪烷分别作为双原子和五原子合成子，参与 
<smiles>[R]c1oc2c3c1CCCC23[R]</smiles>

97

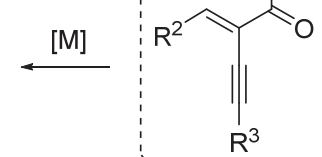

96

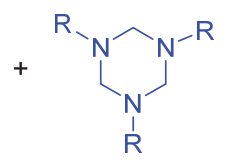

15

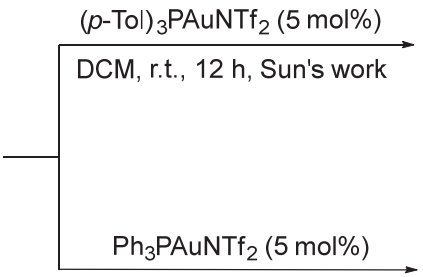

DCE, $40{ }^{\circ} \mathrm{C}, 10 \mathrm{~h}$, Xu's work

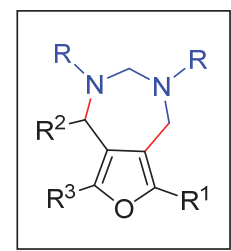

98
图式 31 金催化炔烯酮与三嗪烷 $[4+3]$ 环加成 Scheme 31 Gold-catalyzed [4+3] cycloadditions of 2-(1-alkynyl)-2-alken-1-ones with triazinanes

$[5+2]$ 环加成反应. 该反应涉及到 $\mathrm{C}-\mathrm{N}$ 键生成以及 $\mathrm{C}-\mathrm{C}$ 键断裂, 并且苯甲醛是唯一的副产物. 该过程简 单实用且对环境无害.

$N$-磺酰基-1,2,3-三氮唑可通过铜催化炔-叠氮化物 的环加成反应顺利制得，在适当的过渡金属催化剂作用 下, 可转化为 $\alpha$-亚氨基金属卡宾, 因此引起了有机化学 工作者极大的研究兴趣 ${ }^{[65-71]}$. 鲍晓光等 ${ }^{[72]}$ 报道了一种铑 催化三氮唑 $[2+5]$ 环化合成八氢嘌呤 105 骨架的方法 (Scheme 33). 机理研究表明, 与金催化 ${ }^{[42]}$ 三嗪烷与重氮 $[2+2+1]$ 环加成的反应不同, 该反应中 $1,3,5$-三嗪烷直
接对三氮唑产生的亚胺铑卡宾 106 进行亲核进攻，随后 发生 $[6+3]$ 环加成环化产生九元环中间体 109, 紧接着 分子内亲核加成以及重排得到最终的八氢嘌呤产物 105 (Scheme 34).

\section{5 结论与展望}

综上所述, 1,3,5-三嗪烷作为含氮砌块, 实现众多含 氮杂环化合物的构建, 取得了一定的进展, 但仍具有较 大的研究潜力和发展空间. 在已报道的例子中，1,3,5-三 嗪烷参与反应的形式有两种: 一种是 1,3,5-三嗪烷直接 参与反应，另一种则是 $1,3,5$-三嗪烷先转化成甲醛亚胺, 再参与反应. 目前还没有明确的反应规律，并且无论是 哪一种反应形式, 都存在着 1,3,5-三嗪烷部分片断无法 被利用的问题，同时 1,3,5-三嗪烷作为五原子或者六原 子合成子参与构建大环的报道还较少. 另外利用光催化 和电催化的绿色合成研究还较少, 因此, 期望未来有更 多的工作致力于使用绿色环保的方法, 深入探索和拓展 1,3,5-三嗪烷的环加成反应，并将其运用于构建活性药 物分子或其骨架，这对开发新型氮杂环类药物分子具有 重要价值. 相信随着科学技术的进步以及科研工作者的 努力, 将可开发出更多利用 1,3,5-三嗪烷合成氮杂环化 合物的方法, 拓展 1,3,5-三嗪烷参与的各式各样的反应 类型，进一步推动杂环化合物在药物合成、有机化学和 生命科学等重要领域的发展.
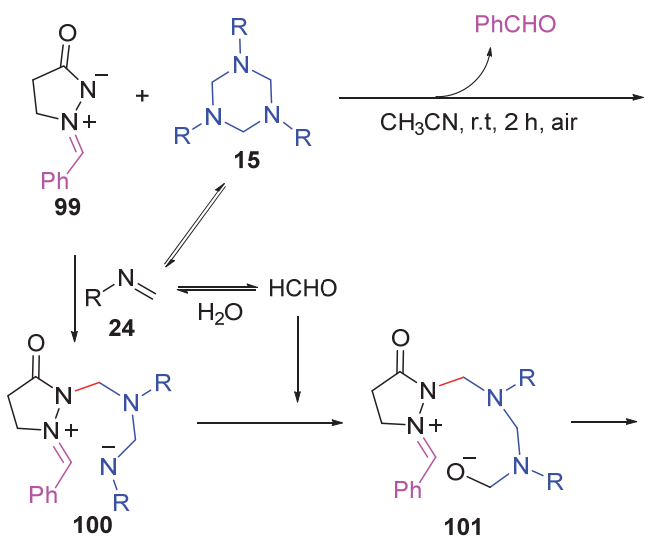<smiles>[R]N1CN([R])CN2C(=O)CCN2C1</smiles>

103<smiles>CCCPC=O</smiles>

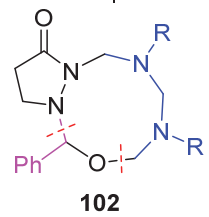

图式 32 亚胺叶立德与三嗪烷 $[5+2]$ 环加成

Scheme $32[5+2]$ cycloaddition of azomethine imines with triazinanes<smiles>[R]c1cn([13CH2])nn1</smiles>

15

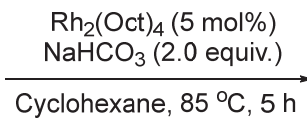

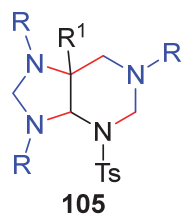

图式 33 铑催化 1,2,3-三氮唑与 1,3,5-三嗪烷的环化反应

Scheme 33 Rh-catalyzed cyclization of 1,3,5-triazinanes with 1,2,3-triazoles 


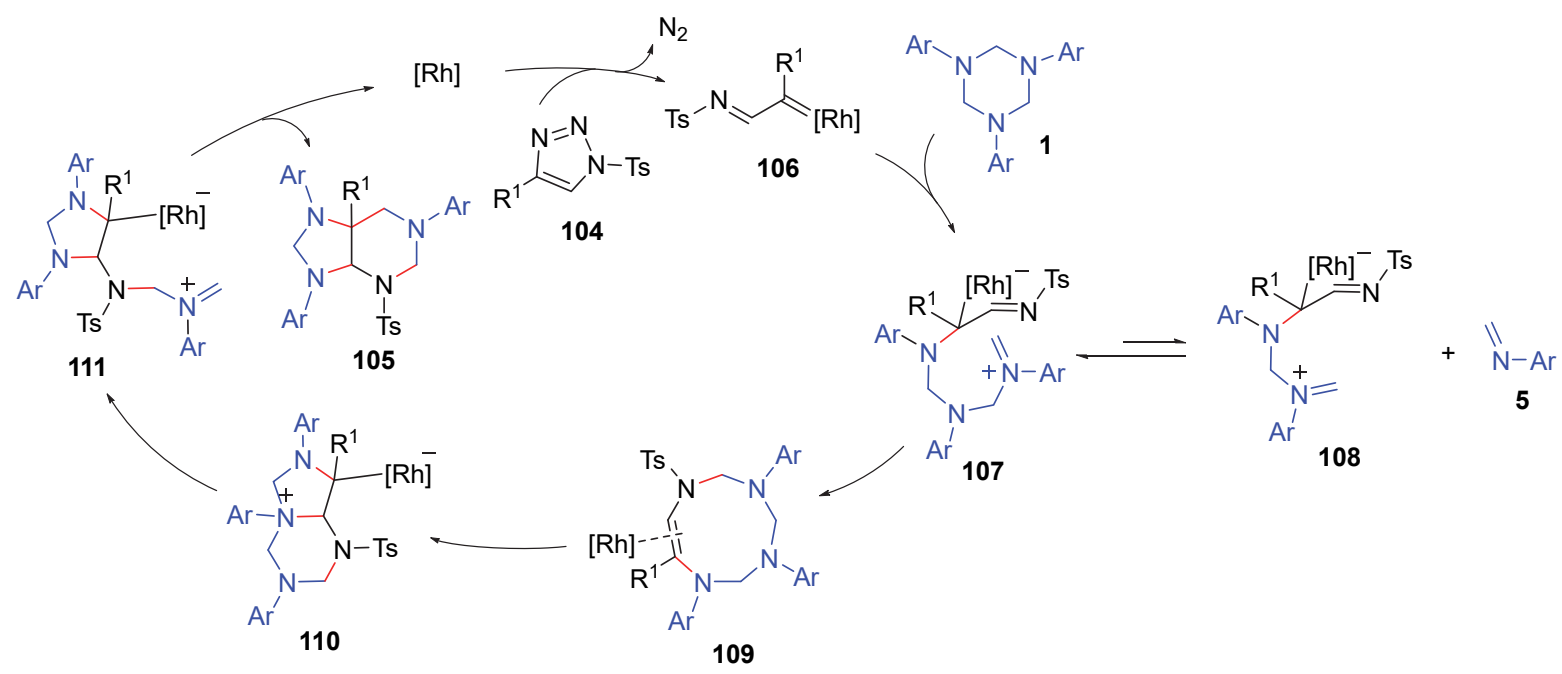

图式 34 1,2,3-三氮唑与 1,3,5-三嗪烷可能的反应机理

Scheme 34 Possible mechanism of 1,3,5-triazinanes with 1,2,3-triazoles

\section{References}

[1] (a) Tang, Y.; Zhang, J.; Zhang, S.; Geng, R.; Zhou, C. Chin. J. Chem. 2012, 30, 1831.

(b) Yu, K.; Gao, B.; Ding, H. Acta Chim. Sinica 2016, 74, 410 (in Chinese).

(余宽, 高北岭, 丁寒锋, 化学学报, 2016, 74, 410.)

(c) Liu, J.; Lin, Z.; Chen, H.; Guo, H.; Tao, J.; Liu, W. Chin. J. Chem. 2019, 37, 35.

(d) Ye, Z.; Zhang, F. Chin. J. Chem. 2019, 37, 513.

(e) Mu, B. S.; Zhang, Z. H.; Wu, W. B.; Yu, J. S.; Zhou, J. Acta Chim. Sinica 2021, 79, 685 (in Chinese).

(穆博帅, 张志豪, 武文彪, 余金生, 周剑, 化学学报, 2021，79, 685.)

[2] Zheng, Y.; Chi, Y.; Bao, M.; Qiu, L.; Xu, X. J. Org. Chem. 2017, $82,2129$.

[3] Ha, H.-J.; Choi, C.-J.; Ahn, Y.-G.; Yun, H.; Dong, Y.; Lee, W. K. J. Org. Chem. 2000, 65, 8384.

[4] Oda, S.; Sam, B.; Krische, M. J. Angew. Chem., Int. Ed. 2015, 54, 8525.

[5] Oda, S.; Franke, J.; Krische, M. J. Chem. Sci. 2016, 7, 136.

[6] Lian, X.; Lin, L.; Fu, K.; Ma, B.; Liu, X.; Feng, X. Chem. Sci. 2017, 8,1238

[7] Gong, J.; Li, S.-W.; Qurban, S.; Kang, Q. Eur. J. Org. Chem. 2017, 3584 .

[8] Liu, R.; Liu, J.; Wei, Y.; Shi, M. Org. Lett. 2019, 21, 4077.

[9] Ruscoe, R. E.; Callingham, M.; Baker, J. A.; Korkis, S. E.; Lam, H. W. Chem. Commun. 2019, 55, 838.

[10] Wang, Y.; Zheng, H.; Xu, J.; Zhuang, C.; Liu, X.; Cao, H. Org. Chem. Front. 2021, 10. 1039/d1qo00883h.

[11] Peng, S.; Ji, D.; Sun, J. Chem. Commun. 2017, 53, 12770.

[12] Schneider, T. F.; Kaschel, J.; Werz, D. B. Angew. Chem., Int. Ed. 2014, 53, 5504 .

[13] Grover, H. K.; Emmett, M. R.; Kerr, M. A. Org. Biomol. Chem. 2015, 13, 655 .

[14] Singh, P.; Varshnaya, R. K.; Dey, R.; Banerjee, P. Adv. Synth. Catal. 2020, 362, 1447.

[15] Pirenne, V.; Muriel, B.; Waser, J. Chem. Rev. 2021, 121, 227.

[16] Wang, J.; Blaszczyk, S. A.; Li, X.; Tang, W. Chem. Rev. 2021, 121, 110.

[17] Garve, L. K. B.; Kreft, A.; Jones, P. G.; Werz, D. B. J. Org. Chem. 2017, 82, 9235.

[18] Chu, Z.-Y.; Li, N.; Liang, D.; Li, Z.-H.; Zheng, Y.-S.; Liu, J.-K. Tetrahedron Lett. 2018, 59, 715 .

[19] Tu, L.; Li, Z.; Feng, T.; Yu, S.; Huang, R.; Li, J.; Wang, W.; Zheng,
Y.; Liu, J.-K. J. Org. Chem. 2019, 84, 11161.

[20] Shi, Z.; Fan, T.; Zhang, X.; Zhan, F.; Wang, Z.; Zhao, L.; Lin, J.-S.; Jiang, Y. Adv. Synth. Catal. 2021, 363, 2619.

[21] Zhang, X.; Cheng, B.; Li, H.; He, Y.; Xu, W.; Duan, X.; Sun, H.; Wang, T.; Zhai, H. Adv. Synth. Catal. 2021, 363, 565.

[22] Ji, D.; Sun, J. Org. Lett. 2018, 20, 2745.

[23] Zhang, C.-B.; Dou, P.-H.; You, Y.; Wang, Z.-H.; Zhou, M.-Q.; Xu, X.-Y.; Yuan, W.-C. Tetrahedron 2019, 75, 130571.

[24] Ji, D.; Wang, C.; Sun, J. Org. Lett. 2018, 20, 3710.

[25] Zheng, Y.; Tu, L.; Li, N.; Huang, R.; Feng, T.; Sun, H.; Li, Z.; Liu, J.-K. Adv. Synth. Catal. 2019, 361, 44.

[26] Liang, D.; Tan, L.-P.; Xiao, W.-J.; Chen, J.-R. Chem. Commun. 2020, 56, 3777.

[27] Cheng, X.; Zhou, S.-J.; Xu, G.-Y.; Wang, L.; Yang, Q.-Q.; Xuan, J. Adv. Synth. Catal. 2020, 362, 523.

[28] Cheng, B.; Zhang, X.; Zhai, S.; He, Y.; Tao, Q.; Li, H.; Wei, J.; Sun, H.; Wang, T.; Zhai, H. Adv. Synth. Catal. 2020, 362, 3836.

[29] Cheng, X.; Cai, B.-G.; Mao, H.; Lu, J.; Li, L.; Wang, K.; Xuan, J. Org. Lett. 2021, 23, 4109.

[30] Yang, Y.; Yang, W. Chem. Commun. 2018, 54, 12182.

[31] Xu, Y.; Chen, L.; Yang, Y.; Zhang, Z.; Yang, W. Org. Lett. 2019, 21, 6674.

[32] Wang, J.; Zhao, L.; Rong, Q.; Lv, C.; Lu, Y.; Pan, X.; Zhao, L.; Hu, L. Org. Lett. 2020, $22,5833$.

[33] Lu, W.-Y.; Wang, Y.; You, Y.; Wang, Z.-H.; Zhao, J.-Q.; Zhou, M.-Q.; Yuan, W.-C. J. Org. Chem. 2021, 86, 1779.

[34] Yang, L.-C.; Rong, Z.-Q.; Wang, Y.-N.; Yin Tan, Z.; Wang, M.; Zhao, Y. Angew. Chem., Int. Ed. 2017, 56, 2927.

[35] Das, P.; Gondo, S.; Nagender, P.; Uno, H.; Tokunaga, E.; Shibata, N. Chem. Sci. 2018, 9, 3276.

[36] Wei, Y.; Liu, S.; Li, M.-M.; Li, Y.; Lan, Y.; Lu, L.-Q.; Xiao, W.-J.; J. Am. Chem. Soc. 2019, 141, 133.

[37] Xia, C.; Wang, D.-C.; Qu, G.-R.; Guo, H.-M. Org. Chem. Front. 2020, 7, 1474.

[38] Chen, L.; Liu, K.; Sun, J. RSC Adv. 2018, 8, 5532.

[39] Cheng, B.; Li, H.; Hou, J.; Zhang, X.; He, Y.; Sun, H.; Xu, W.; Wang, T.; Zhai, H. J. Org. Chem. 2020, 85, 13339.

[40] Ford, A.; Miel, H.; Ring, A.; Slattery, C. N.; Maguire, A. R.; McKervey M. A. Chem. Rev. 2015, 115, 9981;

[41] Cheng, X.; Cai, B.-G.; Mao, H.; Lu, J.; Li, L.; Wang, K.; Xuan, J. Org. Lett. 2021, 23, 4109.

[42] Zhu, C.; Xu, G.; Sun, J. Angew. Chem., Int. Ed. 2016, 55, 11867.

[43] Liu, P.; Xu, G.; Sun, J. Org. Lett. 2017, 19, 1858.

[44] Liu, P.; Zhu, C.; Xu, G.; Sun, J. Org. Biomol. Chem. 2017, 15, 7743. 
[45] Zhou, Y.; Ma, F.; Lu, P.; Wang, Y. Org. Biomol. Chem. 2019, 17, 8849.

[46] Reis, M. I. P.; Campos, V. R.; Resende, J. A. L. C.; Silva1, F. C.; Ferreira, V. F. Beilstein J. Org. Chem. 2015, 11, 1235.

[47] Peng, S.; Cao, S.; Sun, J. Org. Lett. 2017, 19, 524.

[48] Wang, X.-N.; Yeom, H.-S.; Fang, L.-C.; He, S.; Ma, Z.-X.; Kedrowski, B. L.; Hsung, R. P. Acc. Chem. Res. 2014, 47, 560.

[49] Chen, Y.-B.; Qian, P.-C.; Ye, L.-W. Chem. Soc. Rev. 2020, 49, 8897.

[50] Zhou, X. Y.; Liang, Z. X.; Wang, X. N. Chin. J. Org. Chem. 2021, 41, 1288 (in Chinese) (周欣悦, 梁宗显, 王晓娜, 有机化学, 2021, 41, 1288.)

[51] Hu, Y.-C.; Zhao, Y.; Wan, B.; Chen, Q.-A. Chem. Soc. Rev. 2021, $50,2582$.

[52] Zeng, Z.; Jin, H.; Song, X.; Wang, Q.; Rudolph, M.; Rominger, F.; Hashmi, A. S. K. Chem. Commun. 2017, 53, 4304.

[53] Garve, L. K. B.; Jones, P. G.; Werz, D. B. Angew. Chem. Int. Ed. 2017, 56, 9226.

[54] Liu, F.; Yu, Y.; Zhang, J. Angew. Chem. Int. Ed. 2009, 48, 5505.

[55] Gao, H.; Zhao, X.; Yu, Y.; J. Zhang, Chem.-Eur. J. 2010, 16, 456.

[56] He, T.; Gao, P.; Qiu, Y.-F.; Yan, X.-B.; Liu, X.-Y.; Liang, Y.-M. RSC $A d v .2013,3,19913$.

[57] Wang, Y.; Zhang, P.; Qian, D.; Zhang, J. Angew. Chem., Int. Ed. 2015, 54, 14849.

[58] Qi, J.; Teng, Q.; Thirupathi, N.; Tung, C.-H.; Xu, Z. Org. Lett. 2019, 21, 692 .
[59] Di, X.; Wang, Y.; Wu, L.; Zhang, Z.-M.; Dai, Q.; Li, W.; Zhang, J. Org. Lett. 2019, 21, 3018.

[60] Kardile, R. D.; Chao, T.-H.; Cheng, M.-J.; Liu, R.-S. Angew. Chem., Int. Ed. 2020, 59, 10396.

[61] Liu, S.; Yang, P.; Peng, S.; Zhu, C.; Cao, S.; Li, J.; Sun, J. Chem. Commun. 2017, 53, 1152.

[62] Kamata, M.; Yamashita, T.; Kina, A.; Tawada, M. Endo, S.; Mizukami, A.; Sasaki, M.; Tani, A.; Nakano, Y.; Watanabe, Y.; Furuyama, N.; Funami, M.; Amano, N.; Fukatsu, K. Bioorg. Med. Chem. Lett. 2012, 22, 4769 .

[63] Liang, D.; Xiao, W.-J.; Chen, J.-R. Synthesis 2020, 52, 2469.

[64] Chen, R.; Liu, Q.; Wang, K.-K.; Qi, Y.; Zhou, Y.; Zhang, A.; Meng, T.; Liu, L. Asian J. Org. Chem. 2021, 10, 371.

[65] Chattopadhyay, B.; Gevorgyan, V. Angew. Chem., Int. Ed. 2012, 51, 862.

[66] Gulevich, A. V.; Gevorgyan, V. Angew. Chem., Int. Ed. 2013, 52, 1371.

[67] Davies, H. M. L.; Alford, J. S. Chem. Soc. Rev. 2014, 43, 5151.

[68] Jia, M.; Ma, S. Angew. Chem., Int. Ed. 2016, 55, 9134.

[69] Jiang, Y.; Sun, R.; Tang, X. Y.; Shi, M. Chem.-Eur. J. 2016, 22, 17910.

[70] Xia, Y.; Qiu, D.; Wang, J. Chem. Rev. 2017, 117, 13810.

[71] Li, Y.; Yang, H.; Zhai, H. Chem.-Eur. J. 2018, 24, 12757.

[72] Ge, J.; Wu, X.; Bao, X. Chem. Commun. 2019, 55, 6090. 